\title{
Effectiveness of Modified Sabouraud Medium in Relation to the Bacterial Growth
}

\author{
Cristina Motta Ferreira ${ }^{1 *}$, Dayane Rodrigues Andrade ${ }^{1}$, Vander Silva Souza ${ }^{1}$, Guilherme Motta \\ Antunes Ferreira ${ }^{2}$ and William Antunes Ferreira ${ }^{3}$ \\ ${ }^{1}$ Fundação de Hematologia e Hemoterapia do Amazonas -FHEMOAM \\ ${ }^{2}$ Fundação Universidade do Amazonas-UFAM \\ ${ }^{3}$ Fundação de Dermatologia Tropical e Venereologia Alfredo da Matta -FUAM
}

Received: July 2, 2016; Accepted: August 8, 2016; Published: August 9, 2016

*Corresponding author: Cristina Motta Ferreira, Biochemistry researcher, Fundação de Hematologia e Hemoterapia do Amazonas - FHEMOAM, Av. Constantino Nery, 4397, Chapada, CEP: 69050-002. Manaus-Amazonas-Brazil, Tel No: 55-92-9081315353; 55-92-3655-01-00; E-mail: cris_motta_ferr@yahoo.com.br

\begin{abstract}
Among the diseases caused by fungi, candidiasis and aspergillosis are the most frequent. In the bacteriological routine, there are different culture media used for cultivation of bacteria and fungi. Sabouraud dextrose agar is widely used for the clinical samples cultivation. In some cases, the biological samples show a mixed population of bacteria and fungi. Three culture media for the study were prepared: Mycosel, commercially available fungal medium (Sabouraud dextrose agar), and the Sabouraud dextrose modified medium (study media) with different dilutions of an antibiotic. The effectiveness of the study medium was observed from the comparison of the results of the cultures after the cultured of different samples of selected bacteria. The Modified Sabouraud medium showed effectiveness of $100 \%$. The modified medium proved to be fully efficient and effective in both controlled tests because they completely inhibited the bacterial growth, favoring the acquisition of fungus pure cultures. We can conclude that the Sabouraud medium with the modification proposed in this study proved to be more effective in relation to the Mycosel or Sabouraud media.
\end{abstract}

Keywords: Sabouraud; Fungi; Bacteria; Mycosel; MIC

\section{Introduction}

Among the diseases caused by fungi that affect immune impaired patients and submitted to invasive procedures, candidiasis and aspergillosis are the most frequent [1,2], being Candida sp., which is responsible for $80 \%$ of nosocomial infections, especially hematogenic, with reports of strains with resistance to azoles (fluconazole), standard antifungal agent of choice for treatment, as well as the echinocandins $[1,3]$.

In the bacteriological routine, there are different culture media used for growing of bacteria and fungi and the Sabouraud dextrose agar is widely used for the clinical samples cultivation [4]. In some cases, these samples show a mixed population of bacteria and fungi, and this detail can suppress fungal growth. In its original formulation, the Sabouraud dextrose agar has a $\mathrm{pH}$ of 5.6 , to suppress bacterial growth, favoring the fungus $[4,5]$.
However, even with this selectivity, it has been observed in the FHEMOAM's laboratory routine the growth of bacteria such as Escherichia coli and Staphylococcus aureus for example, on the Sabouraud dextrose medium. This occurs due to genetic flexibility, selective pressure, inappropriate therapy, among others [6], which induce the bacteria to acquire or develop different mechanisms of resistance to different chemical agents [7] such as detergents and antibiotics, which enable their adaptation and survival in the adverse environment, including the hospital $[7,8]$.

Because of the frequent hematogenic infections caused by fungi and the difficulty for obtaining pure cultures from biological samples, we sought to develop a study to assess the effectiveness of a modified culture medium, favoring the growth of fungi, however, selective enough to inhibit the bacterial growth.

\section{Material and Methods}

Three culture media for the study were prepared: Mycosel medium (gold standard), commercially available fungal medium (Sabouraud dextrose agar, pH 5.6), which has in their composition: dextrose $(40 \mathrm{~g})$, peptic digest of animal tissue $(5 \mathrm{~g})$, pancreatic digest of casein $(5 \mathrm{~g})$ and agar $(15 \mathrm{~g})$; and the modified Sabouraud dextrose medium (study media) with different concentrations of the antibiotic meropenem tri-hydrate (BioChimico). The preparation of the media was performed according to the manufacturer's recommendations (HimediaHexasystems, Mumbai, India).

The stock solution of the antibiotic in the concentration of $5.120 \mathrm{mg} / \mathrm{mL}$ was prepared by dissolving $500 \mathrm{mg}$ of lyophilized powder in $100 \mathrm{~mL}$ of water and stored in a freezer at $-20^{\circ} \mathrm{C}$. The dilutions of the antibiotic for the determination of Minimum Inhibitory Concentration (MIC) were performed according to the recommendation of Van Dick, et al. [9] and Clinical and Laboratory Standards Institution (CLSI) [10], where a scale with different concentrations ranging from 0.002 to $256 \mu \mathrm{g} / \mathrm{ml}$ was obtained from the dilution 1:10 of the working solution. 
The effectiveness of the study medium was achieved from the comparison, after culturing, of different samples of multiresistant bacteria like Acinetobacter baumannii (four), Pseudomonas aeruginosa (one), Staphylococcus epidermidis (one) and Staphylococcus haemolyticus (one), obtained from biological routine samples. Standard strain of E. coli (ATCC 25922), S. aureus (ATCC 29213) and Candida albicans (ATCC 36232) were also used as control

The test to verify the efficacy of the modified medium, was conducted preparing a suspension at a concentration $\mathrm{n}-0.5$ of the McFarland standard scale (BD BBL), which corresponds approximately to $10^{8} \mathrm{cfu} / \mathrm{ml}$ for each microorganism studied (routine and control), and subsequently, culturing individually, in parallel, in petri plates containing the Mycosel agar media, commercially available fungal medium (Sabouraud dextrose agar), and modified Sabouraud dextrose agar (study media) The plates were incubated at $35.4^{\circ} \mathrm{C}$ for 48 hours for bacterial and fungal growth observation. This procedure was repeated for each plate containing the different dilutions of the antibiotic that ranged from $0.002 \mathrm{mg} / \mathrm{mL}$ up to $256 \mu \mathrm{g} / \mathrm{mL}$. It was specified as MIC, the lowest concentration of the antibiotic that completely inhibited the bacteria growth. After obtaining the MIC, the study media were prepared and inserted into the laboratory routine in order to observe their effectiveness, for a period of 30 days.

\section{Result and Discussion}

It can be observed that there was a decline of $67 \%$ of the bacterial growth at the time it was used a MIC of $4 \mu \mathrm{g} / \mathrm{mL}$, decreasing to $22 \%$ in the MIC of $8 \mu \mathrm{g} / \mathrm{mL}$, and $0 \%$ in the MIC of $16 \mu \mathrm{g} / \mathrm{mL}$, showing that at this concentration the inhibition of all bacterial growth used in the study (graph 1) has occurred, and the Modified Sabouraud medium showed effectiveness of $100 \%$. The 55 plates of Sabouraud modified agar that were inserted in the laboratory routine for 30 days, proved to be efficient and effective, because there was the inhibition of bacterial growth and favoring the growth of fungal cultures, confirmed morphologically by Gram staining and by automated tests (VITEK- 2 COMPACT), (table 1). On the other hand, the Mycosel medium (gold standard) and commercially available Sabouraud dextrose agar in its original formulation, were not efficient enough to prevent bacterial growth.

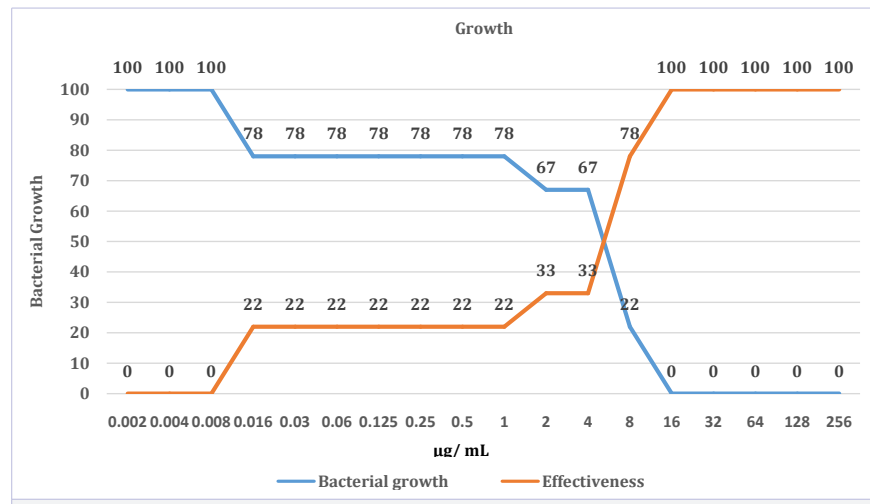

Graph 1: Effectiveness of Modified Sabouraud Medium in relation to the Bacterial Growth.
Table 1: Identified fungi from pure culture of the Sabouraud Modified agar.

\begin{tabular}{|l|c|}
\hline Fungal species/yeasts & n \\
\hline Yeasts & 20 \\
\hline C. albicans & 6 \\
\hline C. tropicalis & 4 \\
\hline Cryptococcus neoformans & 3 \\
\hline C. famata & 1 \\
\hline C. guilliermondii & 1 \\
\hline C. lusitaniae & 1 \\
\hline C. parapsilosis & 1 \\
\hline \multicolumn{1}{|c|}{ TOTAL } & $\mathbf{3 7}$ \\
\hline
\end{tabular}

Different selective media have been widely used in the bacteriology routine to differentiate one group of organism from another to minimize the laboratory's procedures and reduce costs. Currently, the media options available for the cultivation of fungi are still limited $[11,12]$ and the use of selective culture media for each pathogen to be isolated, is paramount. In the case of mixed cultures where the objective of the diagnosis is the fungus, it is necessary to use a medium that prevents bacterial growth and promotes the attainment of fungus pure culture $[5,11]$. The modification performed on Sabouraud agar medium with the addition of the antibiotic, arose from the need to completely abolish the bacterial flora, because some species prevent fungal growth due to toxin production or bacterial overgrowth [5,11-13]. In this context, the modified medium proved to be fully efficient and effective in both controlled tests, and the ones submitted to routine, because they completely inhibited the bacterial growth, favoring the acquisition of pure fungal cultures.

In this study, the use of only one wide spectrum antibiotic, whose MIC of choice for use in routine was of $16 \mu \mathrm{g} / \mathrm{ml}$ was considered sufficient to inhibit the growth of multiresistant bacteria. Other authors have also performed similar methodologies; however, they made antibiotics combinations or used two types of culture medium to obtain the fungi growth $[11,14]$.

In many cases, the fungi are the pathogens responsible for the deterioration of the clinical condition, and for hospitalized patients, the consequences due to delay of the clinical diagnosis, can be fatal. These facts increase the importance and necessity of the use of specific selective medium for obtaining pure fungus culture and species identification [5]. Therefore, we can conclude that the Sabouraud medium with the modification proposed in this study proved to be more effective in relation to the Mycosel or Sabouraud media, in their original formulation, and the fact that these last ones have not inhibited the bacterial growth, make the modified tested, a practical option for daily use in bacteriological routine, especially when there is clinical indication, or the need for additional tests as the antifungal susceptibility test. 


\section{References}

1. Antimicrobial resistance: global report on surveillance.2014. http:// www.who.int/drugresistance/en/

2. Cornely OA, Cuenca-Estrella M, Meis JF, Ullmann AJ. European Society of Clinical Microbiology and Infectious Diseases (ESCMID) Fungal Infection Study Group (EFISG) and European Confederation of Medical Mycology (ECMM) 2013 joint guidelines on diagnosis and management of rare and emerging fungal diseases. Clinical Microbiology and Infection. 2014;20(3):1-4.

3. Teixeira-Loyola ABA, Fernandes AP, Barbosa CC, Mattozo JMA, Silva AC, Schreiber AZ. Ocorrência e perfil de suscetibilidade de Candida sp em hemoculturas de um hospital universitário: Occurrence and Susceptibility profile of Candida sp in Blood Cultures from a University Hospital. Medicina (Ribeirão Preto). 2013;46(4):398-403.

4. Odds FC. Sabouraud ('s) agar. J Med Vet Mycol. 1991;29(6):355-9.

5. Sandven P, Lassen J. Importance of Selective Media for Recovery of Yeasts from Clinical Specimens. J Clin Microbiol. 1999;37(11):3731-2.

6. Ferreira CM, Naveca FG, Ferreira WA, de Oliveira CM, Barbosa Md Novel methicillin-resistant coagulase-negative Staphylococcus clone isolated from patients with haematological diseases at the Blood Bank Centre of Amazon, Brazil. Mem Inst Oswaldo Cruz. 2013;108(2):2338.
7. Daza PRM. Resistencia bacteriana a antimicrobianos: su importância en la toma de decisiones en la práctica diária. Inf Ter Sist Nac Salud.1998;22(3):57-67.

8. Tavares W. [Problems with gram-positive bacteria: resistance in staphylococci, enterococci, and pneumococci to antimicrobial drugs]. Rev Soc Bras Med Trop. 2000;33(3):281-301.

9. Van Dick E, Meheus AZ, Piot P. Laboratory diagnosis of sexually transmitted diseases. WHO, Geneva. 1999;135.

10. Clinical and Laboratory Standards Institute. Performance standards for antimicrobial susceptibility testing; 25th Informational Suplement M100-S25, CLSI, Wayne. 2015;35(3):240.

11. Nagano Y, Millar BC, Goldsmith CE, Walker JM, Elborn JS, Rendall J et al. Development of selective media for the isolation of yeasts and filamentous fungi from the sputum of adult patients with cystic fibrosis (CF). J Cyst Fibros. 2008;7(6):566-72. doi: 10.1016/j.jcf.2008.06.007.

12. Basu S, Bose C, Ojha N, Das N, Das J, Pal M, et al. Evolution of bacterial and fungal growth media. Bioinformation. 2015;11(4):182-4. doi: $10.6026 / 97320630011182$.

13. Lima KM, Rêgo RSM, Montenegro F. Espécies fúngicas isoladas a partir de unhas de manipuladores de alimentos. RBAC. 2007;39(3):193-196.

14. Guinea J, Peláez T, Alcalá L, Bouza E. Evaluation of Czapeck agar and Sabouraud dextrose agar for the culture of airborne Aspergillus conidia. Diagn Microbiol Infect Dis. 2005;53(4):333-4. 